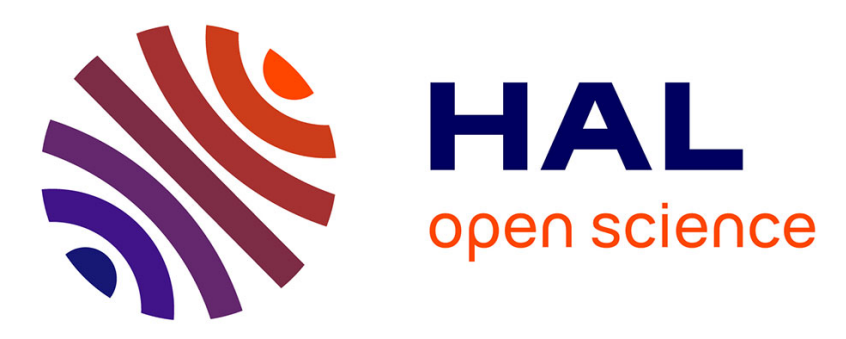

\title{
Role of the Ge surface during the end of range dissolution
}

S. Boninelli, G. Impellizzeri, A. Alberti, F. Priolo, Fuccio Cristiano, C.

Spinella

\section{- To cite this version:}

S. Boninelli, G. Impellizzeri, A. Alberti, F. Priolo, Fuccio Cristiano, et al.. Role of the Ge surface during the end of range dissolution. Applied Physics Letters, 2012, 101 (16), pp.162103. 10.1063/1.4759031 . hal-01921897

\section{HAL Id: hal-01921897 https://hal.science/hal-01921897}

Submitted on 14 Nov 2018

HAL is a multi-disciplinary open access archive for the deposit and dissemination of scientific research documents, whether they are published or not. The documents may come from teaching and research institutions in France or abroad, or from public or private research centers.
L'archive ouverte pluridisciplinaire HAL, est destinée au dépôt et à la diffusion de documents scientifiques de niveau recherche, publiés ou non, émanant des établissements d'enseignement et de recherche français ou étrangers, des laboratoires publics ou privés. 


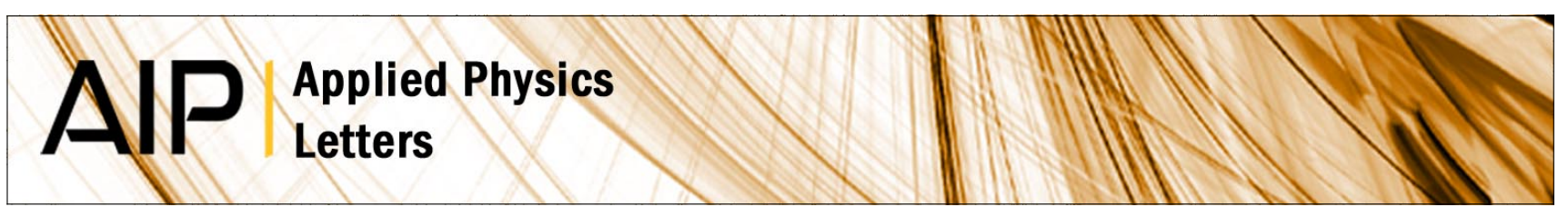

\section{Role of the Ge surface during the end of range dissolution}

S. Boninelli, G. Impellizzeri, A. Alberti, F. Priolo, F. Cristiano et al.

Citation: Appl. Phys. Lett. 101, 162103 (2012); doi: 10.1063/1.4759031

View online: http://dx.doi.org/10.1063/1.4759031

View Table of Contents: http://apl.aip.org/resource/1/APPLAB/v101/i16

Published by the American Institute of Physics.

\section{Related Articles}

The origin of $0.78 \mathrm{eV}$ line of the dislocation related luminescence in silicon

J. Appl. Phys. 112, 063528 (2012)

Growth regimes during homoepitaxial growth of GaN by ammonia molecular beam epitaxy

J. Appl. Phys. 112, 054903 (2012)

Defect microstructural evolution in ion irradiated metallic nanofoils: Kinetic Monte Carlo simulation versus cluster dynamics modeling and in situ transmission electron microscopy experiments

Appl. Phys. Lett. 101, 101905 (2012)

Anisotropic lattice relaxation in non-c-plane InGaN/GaN multiple quantum wells

J. Appl. Phys. 112, 033513 (2012)

Analysis of doping induced wafer bow during GaN:Si growth on sapphire

J. Appl. Phys. 112, 033503 (2012)

\section{Additional information on Appl. Phys. Lett.}

Journal Homepage: http://apl.aip.org/

Journal Information: http://apl.aip.org/about/about_the_journal

Top downloads: http://apl.aip.org/features/most_downloaded

Information for Authors: http://apl.aip.org/authors

\section{ADVERTISEMENT}

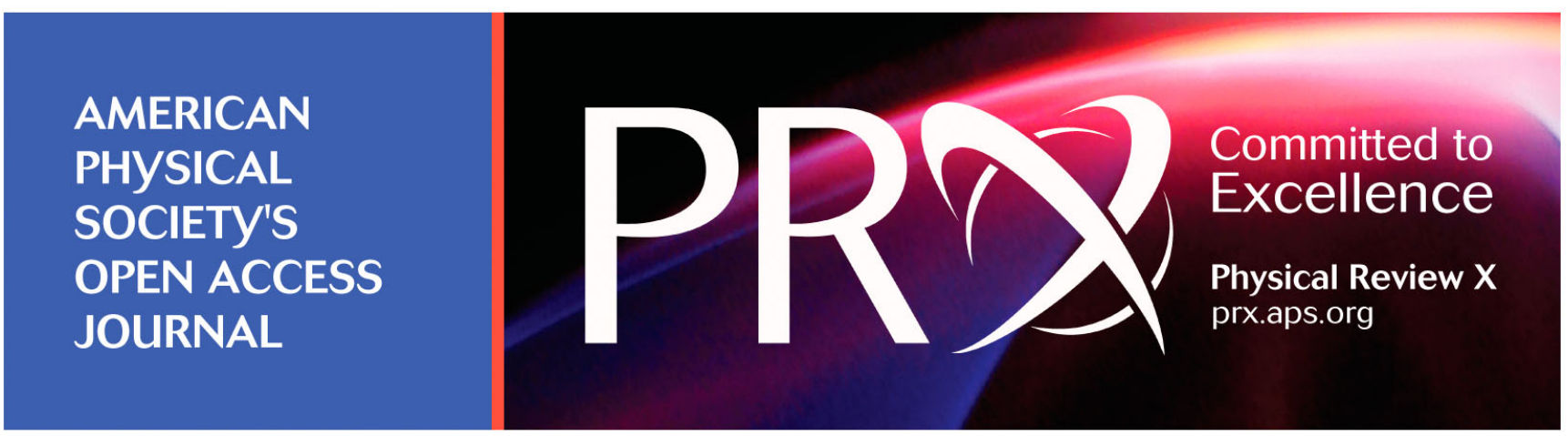




\title{
Role of the Ge surface during the end of range dissolution
}

\author{
S. Boninelli, ${ }^{1, \text { a) }}$ G. Impellizzeri, ${ }^{1}$ A. Alberti, ${ }^{2}$ F. Priolo, ${ }^{1}$ F. Cristiano,,${ }^{3,4}$ and C. Spinella ${ }^{2}$ \\ ${ }^{1}$ CNR-IMM MATIS and Dipartimento di Fisica e Astronomia, Università di Catania, Via S. Sofia 64, \\ 95123 Catania, Italy \\ ${ }^{2}$ CNR-IMM, VIII Strada 5, 95121 Catania, Italy \\ ${ }^{3}$ LAAS-CNRS, 7, Avenue du Colonel Roche, F-31400 Toulouse, France \\ ${ }^{4}$ Université de Toulouse, LAAS, F-31400 Toulouse, France
}

(Received 10 July 2012; accepted 1 October 2012; published online 16 October 2012)

\begin{abstract}
We investigated the structure of end-of-range (EOR) defects in Ge and the role played by the surface during their dissolution caused by annealing. Ge samples were amorphized with $\mathrm{Ge}^{+}$ions at two different energies (30 and $100 \mathrm{keV})$ in order to induce, after solid phase epitaxial regrowth, the formation of EOR band at different depths. High resolution x-ray diffraction and transmission electron microscopy showed that the EOR population consists mainly on small defects and few dislocation loops lying on $\langle 001\rangle$ planes. The deepest EOR defects are more stable during thermal annealing demonstrating the role of the surface during their dissolution. (C) 2012 American Institute of Physics. [http://dx.doi.org/10.1063/1.4759031]
\end{abstract}

Germanium is today considered a good candidate to complement $\mathrm{Si}$ in advanced microelectronic devices because of the higher mobility of holes and electrons, ${ }^{1,2}$ the compatibility with the Si manufacturing processes, and the higher dopant solubility. ${ }^{3}$

Similarly to $\mathrm{Si}$, a pre-amorphization step, followed by dopant implantation, can be used to reduce the channeling phenomenon so to realize ultra-shallow junctions. However, the subsequent thermal treatments, necessary to re-crystallize the material by solid phase epitaxy (SPE), induce the formation of interstitial-type end-of-range (EOR) defects behind the original amorphous-crystalline interface $(\mathrm{a} / \mathrm{c}){ }^{4,5}$ These defects evolve during post-SPE thermal annealing, inducing detrimental effects on the diffusion and electrical activation of the dopant. Indeed, Napolitani et al. ${ }^{6}$ demonstrated that in Ge (as in $\mathrm{Si}$ ), the dissolution of EOR damage induces a transient enhanced diffusion of $\mathrm{B}$, while Panciera et al. ${ }^{7}$ showed that Ge self-interstitials, released by EOR defects, are one of the causes of B deactivation.

In literature, the typology and the thermal evolution of EOR defects in Ge is still unclear. Satta et al. ${ }^{8}$ did not detect by transmission electron microscopy (TEM) any defect in a Ge sample implanted with $1 \times 10^{15} \mathrm{Ge} / \mathrm{cm}^{2}$ at $100 \mathrm{keV}$ and annealed at $400{ }^{\circ} \mathrm{C}$ for $60 \mathrm{~s}$. On the contrary, Panciera et al. ${ }^{7}$ observed by TEM that EOR defects not only form but also survive after an annealing at $400{ }^{\circ} \mathrm{C}$ for $100 \mathrm{~s}$ while they completely disappear after $900 \mathrm{~s}$ in agreement with results shown by our group. ${ }^{9}$ In addition, Hickey et al. ${ }^{10}$ observed that Ge implanted with $1 \times 10^{15} \mathrm{Si} / \mathrm{cm}^{2}$ at $1 \mathrm{MeV}$ creates a buried amorphous layer that, upon regrowth, exhibits EOR defects that dissolve only at temperature above $550{ }^{\circ} \mathrm{C}$. The different behavior in all these defects might be due to the different experimental conditions. Indeed, it is well known that in $\mathrm{Si}$, the surface acts as a recombination center for selfinterstitials released from the EOR defects ${ }^{11}$ while less it is known in Ge. Thus, our aim in this letter is to shed light on the role of the Ge surface on the EOR defects dissolution.

\footnotetext{
${ }^{\text {a) }}$ Author to whom correspondence should be addressed. Electronic mail: simona.boninelli@ct.infn.it.
}

Ge Czochralski wafers, (100)-oriented, $p$-type (with a resistivity higher than $40 \Omega \cdot \mathrm{cm}$ ) were implanted with a fluence of $2 \times 10^{14} \mathrm{Ge} / \mathrm{cm}^{2}$ at $30 \mathrm{keV}$ or at $100 \mathrm{keV}$. The implanted fluence of $2 \times 10^{14}$ is in both cases above the amorphization threshold. ${ }^{12}$ In order to study the thermal evolution of EOR defects, the as-implanted samples were cut into small pieces and were subjected to various thermal treatments in a conventional furnace under a controlled $\mathrm{N}_{2}$ flux at $340{ }^{\circ} \mathrm{C}, 370^{\circ} \mathrm{C}$, or $400^{\circ} \mathrm{C}$ for $1 \mathrm{~h}$. TEM analyses were performed with a $200 \mathrm{keV} 2010$ JEOL instrument to investigate the damage induced by the ionimplantation. Plan view (PV) and cross-section (CS) samples were prepared by means of standard preparation with mechanical grinding and ion milling performed in a GATAN-PIPS apparatus at low energy $(3 \mathrm{keV} \mathrm{Ar})$ and low incidence angle $\left(7^{\circ}\right)$ to minimize the irradiation damage. High-resolution $\mathrm{x}$-ray diffraction (HR-XRD) measurements were performed by using a D8 Discover Bruker AXS diffractometer equipped with a $\mathrm{k} \alpha \mathrm{Cu}$ source and a 4 bounce (022) asymmetric Ge monocromator with an instrumental broadening as low as $\sim 0.005$, to study the effect of the implant on the Ge matrix.

The two energies of 30 and $100 \mathrm{keV}$ of the $\mathrm{Ge}^{+}$ion implantation where chosen to obtain two different amorphous thicknesses. The $30 \mathrm{keV}$ implant induces the formation of an amorphous layer from the surface down to a depth of $\sim 20 \mathrm{~nm}$, while the $100 \mathrm{keV}$ implant induces an amorphous layer extending from the surface down to a depth of $\sim 90 \mathrm{~nm}$, as verified by TEM analyses (not shown). We evaluated by SRIM (stopping and range of ions in matter) ${ }^{13}$ simulations the concentrations of excess interstitials created by the two implants below the a/c interface. The estimated values are $\sim 1.7 \times 10^{16} \mathrm{~cm}^{-2}$ for the $30 \mathrm{keV}$ implanted sample, and $\sim 1.6 \times 10^{16} \mathrm{~cm}^{-2}$ for the $100 \mathrm{keV}$ implant. Since the excess of interstitials created by the two implants has been evaluated to be the same, we can conclude that any difference on the defect populations is attributed to their distance from the surface. After the ion implantation process, the samples were annealed at $340^{\circ} \mathrm{C}$ for $1 \mathrm{~h}$ to induce the SPE regrowth.

HR-XRD $\omega-2 \theta$ diffraction patterns were collected around the (004) Ge reciprocal lattice point, and represented as a function of the deviation $\left(\Delta \mathbf{q}_{\mathbf{z}}\right)$ from the [004] reciprocal 
lattice vector $\mathbf{q}_{\mathbf{z}}\left(\mathbf{q}_{\mathbf{z}}=\mathbf{\Delta} \mathbf{k}\right.$, where $\left.|\mathrm{k}|=2 \pi / \lambda, \lambda=1.5406 \AA\right)$. In the reciprocal space, the scan represents a section through the reciprocal lattice point along the direction of $\mathbf{q}_{\mathbf{z}}$ and around the $\left|\mathbf{q}_{\mathbf{z 0 0 4}}\right|$ value. The diffraction pattern collected in the sample implanted at $100 \mathrm{keV}$ shows a large diffuse scattering around the Bragg peak position as an effect of the amorphization of the Ge matrix and partially due to the formation of point defects behind the amorphized depth. After annealing at $340^{\circ} \mathrm{C}$, the diffuse scattering contribution due to the amorphization is recovered, whilst the intensity of the radiation diffused at angles higher than the Bragg reflection stays above that of a germanium reference pattern, over a certain angular extent, as shown by the vertical dashed lines in Fig. 1(a). It is well known ${ }^{14}$ that the sign of the asymmetry in the diffuse scattering is related to the sign of the displacement field around the defects, and thus to the nature of the defects. Since, in our case, the asymmetry is above the critical angle, it can be concluded ${ }^{14}$ that the defects left by the
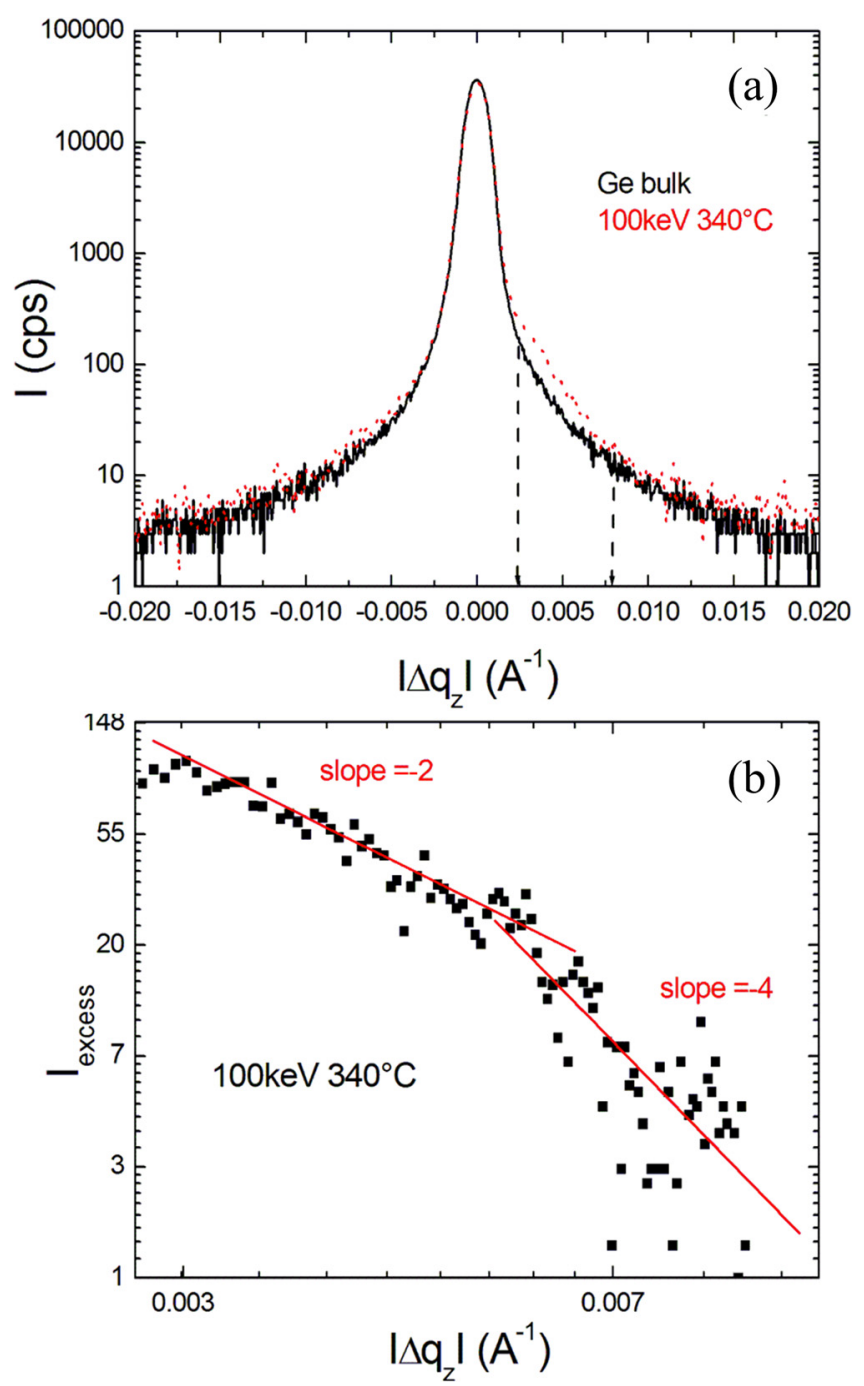

FIG. 1. (a) HR-XR diffraction pattern of the sample implanted at $100 \mathrm{keV}$ and after annealing at $340^{\circ} \mathrm{C}$, compared to that of an unimplanted Ge bulk sample: it has a shoulder at angle above the Bragg one due to diffuse scattering from interstitial-type defects; (b) double log plot of the exceeding intensity, in the region among dashed lines in (a), as a function of $\left|\Delta q_{z}\right|$ showing the Huang contribution depending on $\Delta \mathrm{q}^{-2}$, which indicates the presence of interstitial clusters. implant after the SPE process are interstitials atoms, in agreement with results present in literature. ${ }^{4,5}$ In Fig. 1(b), the excess of diffuse scattering $\left(\mathrm{I}_{\text {excess }}\right)$ with respect to the reference contribution (calculated in the region marked by dashed lines on the right hand side of the peak) is shown in a double logarithmic plot as a function of $\left|\Delta \mathrm{q}_{\mathrm{z}}\right|$. It has to be noted that the curve has a double slope: in the low values range, the excess of intensity decreases as $\Delta \mathrm{q}^{-2}$ due to the Huang scattering from the lattice atoms near the defects while at higher values it decays roughly as $\Delta \mathrm{q}^{-4}$ due to the Stokes-Wilson scattering. ${ }^{14}$ This kind of behaviour, wherein the Huang scattering contribution depends on $\mathrm{q}^{-2}$, is commonly recognised as due to the presence of clusters of interstitial atoms in a crystalline matrix. ${ }^{14}$

TEM analyses were performed on these samples in order to deeply investigate the microscopic structure of the defect population. In Fig. 2, we compared CS bright field TEM images of the sample implanted at $100 \mathrm{keV}$ [Fig. 2(a)] and at $30 \mathrm{keV}$ [Fig. 2(b)] both annealed at $340^{\circ} \mathrm{C}$. In both cases, EOR defects appear behind the original a/c interface. In particular, the sample implanted at $100 \mathrm{keV}$ shows a $\sim 40 \mathrm{~nm}$ thick EOR band placed $\sim 90 \mathrm{~nm}$ below the surface [Fig. 2(a)]; the sample implanted at $30 \mathrm{keV}$ and re-crystallized shows a much thinner defect band, less than $10 \mathrm{~nm}$ in thickness, with very few EOR defects, placed $\sim 30 \mathrm{~nm}$ below the surface [Fig. 2(b)]. High resolution (HR) images of two different types of EOR defects are reported in the insets of Fig. 2(a). At the left top, a small cluster with a radius of $\sim 2 \mathrm{~nm}$ is reported, whose contrast hinders to resolve its structure. At the right top, a small dislocation loop (DL) with the characteristic "coffee-bean shape" is shown. The fast Fourier transform analysis (not shown) of this HR image reveals that the habit plane of this small DL lies on the $\{001\}$ plane, parallel to the surface. The evidence of DL with these characteristics in
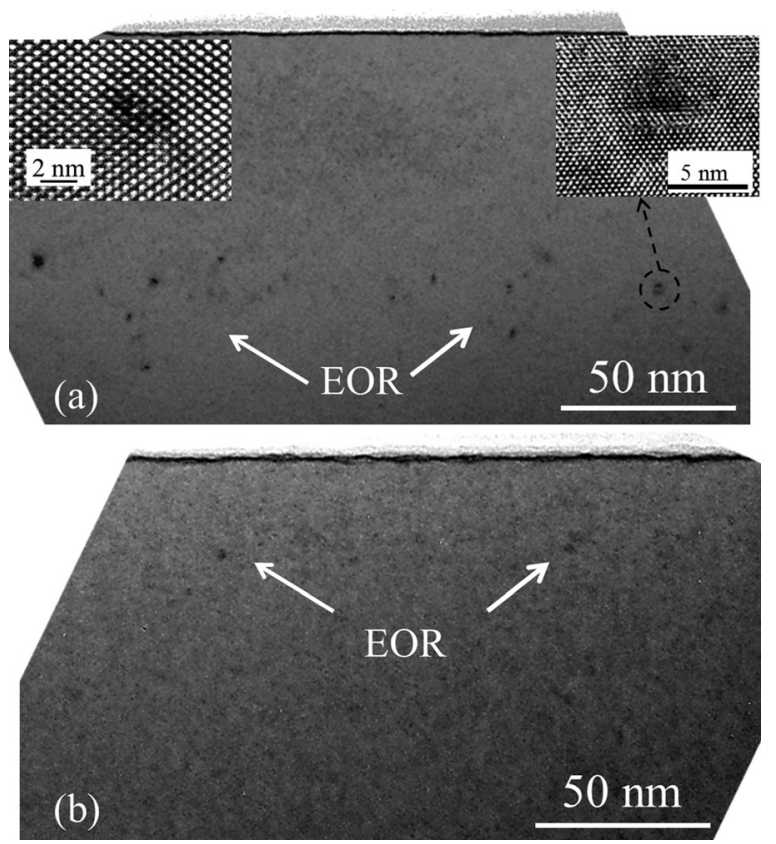

FIG. 2. Cross section TEM of Ge samples implanted with $2 \times 10^{14} \mathrm{Ge} / \mathrm{cm}^{2}$ at $100 \mathrm{keV}$ (a) and $30 \mathrm{keV}$ (b), after annealing at $340^{\circ} \mathrm{C}$ for $1 \mathrm{~h}$. The inset at the left top shows a high resolution image of a small cluster, while the inset at the right top shows a high magnification image of a dislocation loop. 
self-implanted Ge is in agreement with similar results reported in literature. Indeed, Hickey et al..$^{10}$ observed DLs lying on $\{111\}$ planes (see Fig. 3 of Ref. 10) after high energy amorphizing implants, while Takeda et al. ${ }^{15}$ detected defects lying on $\{001\}$ planes after very light ion implantation (deuteron).

To quantitatively estimate the density of the EOR population for different implantation energies and thermal treatments, we analysed the samples by TEM in PV. The EOR defects are usually investigated by TEM in weak beam dark field (WBDF) configuration both in $\mathrm{Si}^{16-18}$ and $\mathrm{Ge},{ }^{5,7,10,19}$ since it allows to visualize the core of the defects with the best contrast. However, since the visibility of each family of defects strongly depends on its crystallographic orientation and on the diffracting $\mathbf{g}$ vector used for the TEM observation, not all the defect families can be observed in a single image. Thus, a deep knowledge of the defect crystallography is necessary to evaluate the whole defect density. In $\mathrm{Si}$, EOR grow significantly in size during thermal annealing, allowing a better microscopic identification of their structure on the basis of the well-known TEM contrast extinction criteria. Conversely, the EOR defects in Ge generally appear as extremely small clusters (whose size is a few $\mathrm{nm}$ ) that do not exhibit any direction of elongation, increasing the difficulty of identifying their crystallographic structure. To overcome this limitation, we employed the alternative "zone axisbright field (ZA-BF)" technique used by Pan et al. ${ }^{20}$ to visualize all the defects, independently of their atomic structures, although with a lower contrast. In Fig. 3, we compared PV TEM of the samples implanted at $100 \mathrm{keV}$ [Fig. 3(a)] and at $30 \mathrm{keV}$ [Fig. 3(b)] and annealed at $340^{\circ} \mathrm{C}$. It is evident that the density of defects in the sample implanted at $100 \mathrm{keV}$ is higher than that present in the sample implanted at $30 \mathrm{keV}$. For the quantification of EOR, in terms of mean diameter and areal density, we should take into account that the TEM sample preparation of $\mathrm{Ge}$ induces the formation of artifacts, which appear in BF images as small (few $\mathrm{nm}$ in diameter) and dark clusters whose contrast and dimensions are similar to those of EOR. This peculiarity of Ge makes the EOR quantification a difficult task. To solve this problem, a virgin Ge TEM sample has been prepared in both CS and PV configuration by identical procedure and treated as a reference (not shown). The analysis of several PV images taken at different magnifications shows that the mean diameter of artifacts is less than $3 \mathrm{~nm}$ and their areal density is about $(1.1 \pm 0.2) \times 10^{10}$ artifacts $/ \mathrm{cm}^{2}$, therefore for the real evaluation of the EOR density produced by Ge implantation, we removed these background counts.

The mean diameter, $\mathrm{d}$, and the effective areal density, $\sigma$, of the EOR defects are reported in Fig. 4 as a function of the different annealing temperatures and of the different implantation conditions. We found $\mathrm{d}=(5 \pm 1) \mathrm{nm}$ and $\sigma=(3.3 \pm 0.2)$ $\times 10^{10}$ defects $/ \mathrm{cm}^{2}$ for the sample implanted at $100 \mathrm{keV}$ (square and circle symbols) and $\mathrm{d}=(4 \pm 1) \mathrm{nm}$ and $\sigma=(0.3 \pm 0.2)$ $\times 10^{10}$ defects $/ \mathrm{cm}^{2}$ for the sample implanted at $30 \mathrm{keV}$ (triangle and stars symbols), both annealed at $340^{\circ} \mathrm{C}$.

Even if the areal density of the $30 \mathrm{keV}$ implanted sample, obtained after the removal of the background, indicates a drastic reduction of the defects density, the mean defect diameter $(\sim 4 \mathrm{~nm})$ is higher than that $(<3 \mathrm{~nm})$ of artifacts in virgin Ge. The trend is confirmed for the annealing at

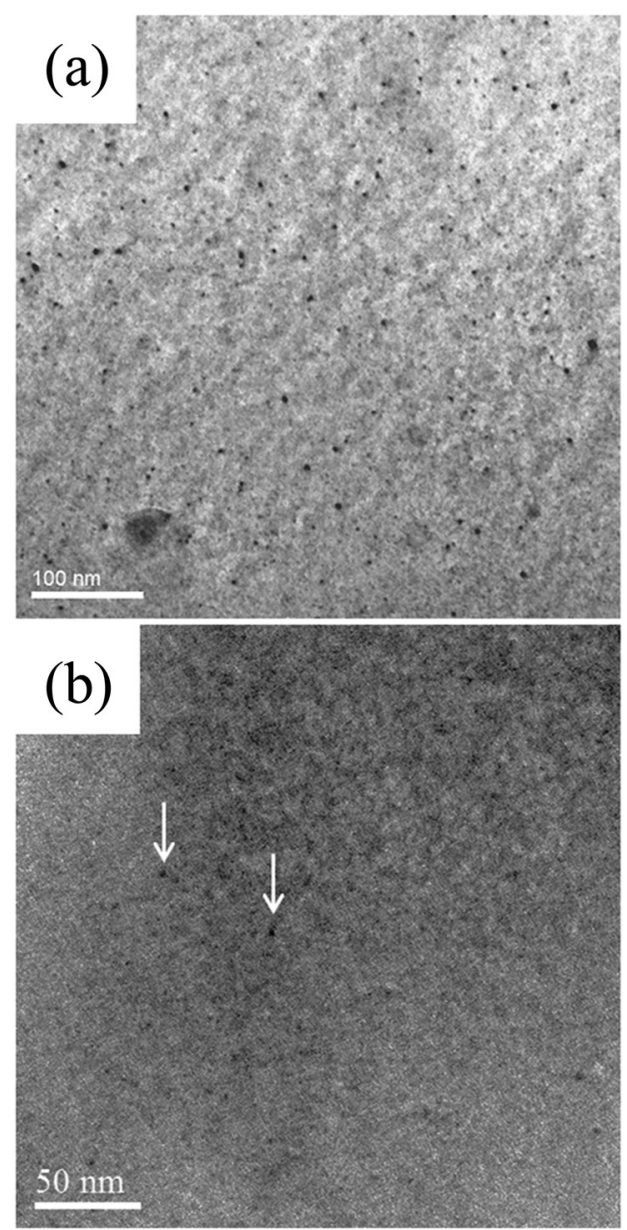

FIG. 3. Plan view TEM images of Ge samples implanted with $2 \times 10^{14} \mathrm{Ge} /$ $\mathrm{cm}^{2}$ at $100 \mathrm{keV}$ (a) and $30 \mathrm{keV}$ (b), after annealing at $340^{\circ} \mathrm{C}$ for $1 \mathrm{~h}$.

$370^{\circ} \mathrm{C}$, in fact we measured $\mathrm{d}=(4 \pm 1) \mathrm{nm}$ and $\sigma=(1.9 \pm 0.2)$ $\times 10^{10}$ defects $/ \mathrm{cm}^{2}$ for the sample implanted at $100 \mathrm{keV}$ and $\mathrm{d}<3 \mathrm{~nm}$ with $\sigma$ around the background value for the sample implanted at $30 \mathrm{keV}$, suggesting a complete dissolution of EOR. Finally, we have no evidence of any defect after annealing at $400^{\circ} \mathrm{C}$ for sample implanted at $100 \mathrm{keV}$.

All these results point out some considerations. First of all, the reduction of the EOR density as a function of the thermal budget, for samples implanted at $100 \mathrm{keV}$, indicates that the defect population tends to shrink and, progressively, to

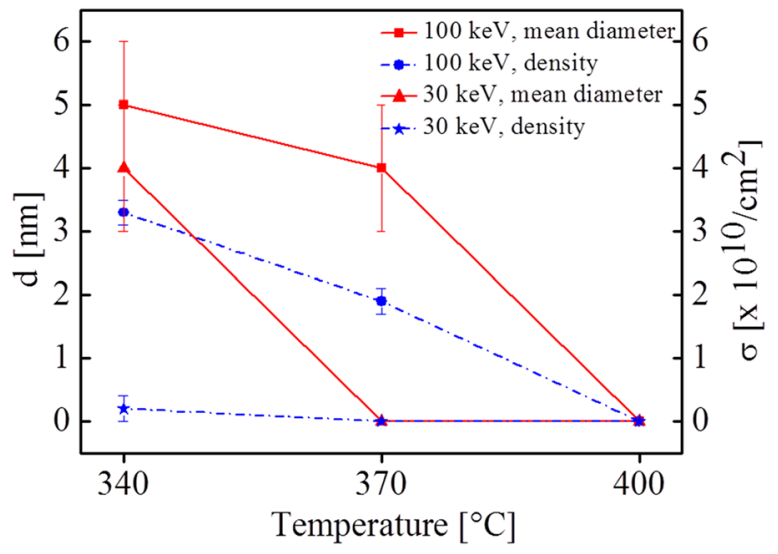

FIG. 4. Evolution of the effective defect mean diameter and the defect density as a function of the temperature. 
dissolve. Moreover, the defect density observed at $340^{\circ} \mathrm{C}$ for the $30 \mathrm{keV}$ implant $\left[(0.3 \pm 0.2) \times 10^{10}\right.$ defects $\left./ \mathrm{cm}^{2}\right]$ is much lower than the one observed in the sample implanted at $100 \mathrm{keV}$ $\left[(3.3 \pm 0.2) \times 10^{10}\right]$ clearly indicating that the proximity of the surface affects the defect stability. This effect is even more evident if we consider the samples annealed at $370^{\circ} \mathrm{C}$; about $60 \%$ of the defects survive for the $100 \mathrm{keV}$ implant [from $(3.3 \pm 0.2) \times 10^{10}$ to $(1.9 \pm 0.2) \times 10^{10}$ defects $\left./ \mathrm{cm}^{2}\right]$, while all defects dissolve for $30 \mathrm{keV}$ implant. These observations strongly suggest that the Ge surface acts as a sink for self-interstitials.

To better clarify the role of the surface, further studies should be conducted: a vacancies injection from the surface or the presence of dangling bonds at the surface could favor the self-interstitials annihilation, strongly altering the defects density. The large variety of results reported in the literature can be easily exploited on the basis of the different distance between the damage and the surface.

In conclusion, we clearly demonstrated by HR-XRD and TEM analyses that EOR defects in Ge are made mainly of small defects and few dislocation loops lying on $\langle 001\rangle$ planes. After an accurate quantitative analysis that has taken also into account the defects background induced by the TEM sample preparation, we observed that these defects dissolve during thermal annealing with a dissolution rate that strongly depends on their proximity to the surface demonstrating a role of the surface in the recombination of the interstitials.

The authors wish to thank C. Percolla and S. Tatì (CNRIMM MATIS) for their expert technical assistance. S.B. is grateful to C. Bongiorno (CNR-IMM) for scientific discussions.
${ }^{1}$ S. M. Sze and J. C. Irvin, Solid State Electron. 11, 599 (1968).

${ }^{2}$ S. Mirabella, G. Impellizzeri, A. M. Piro, E. Bruno, and M. G. Grimaldi, Appl. Phys. Lett. 92, 251909 (2008).

${ }^{3}$ C. Claeys and E. Simoen, Germanium-Based Technologies_From Materials to Devices (Elsevier, Amsterdam, 2007).

${ }^{4}$ G. Bisognin, S. Evangelista, and E. Bruno, Mater. Sci. Eng. B 154-155, 64 (2008).

${ }^{5}$ S. Koffel, N. Cherkashin, F. Houdellier, M. J. Hytch, G. Benassayag, P. Scheiblin, and A. Claverie, J. Appl. Phys. 105, 126110 (2009).

${ }^{6}$ E. Napolitani, G. Bisognin, E. Bruno, M. Mastromatteo, G. G. Scapellato, S. Boninelli, D. De Salvador, S. Mirabella, C. Spinella, A. Carnera, and F. Priolo, Appl. Phys. Lett. 96, 201906 (2010).

${ }^{7}$ F. Panciera, P. F. Fazzini, M. Collet, J. Bedel, and F. Cristiano, Appl. Phys. Lett. 97, 012105 (2010).

${ }^{8}$ A. Satta, E. Simoen, T. Janssens, T. Clarysse, B. De Jaeger, A. Benedetti, I. Hoflijk, B. Brijs, M. Meuris, and W. Vandervorst, Appl. Phys. Lett. 87, 172109 (2005).

${ }^{9}$ S. Boninelli, G. Impellizzeri, F. Priolo, E. Napolitani, and C. Spinella, Nucl. Instrum. Methods B 282, 21 (2012).

${ }^{10}$ D. P. Hickey, Z. L. Bryan, K. S. Jones, R. G. Elliman, and E. E. Haller, Appl. Phys. Lett. 90, 132114 (2007).

${ }^{11}$ D. R. Lim, C. S. Rafferty, and F. P. Klemens, Appl. Phys. Lett. 67, 2302 (1995).

${ }^{12}$ G. Impellizzeri, S. Mirabella, and M. G. Grimaldi, Appl. Phys. A 103, 323 (2011).

${ }^{13}$ J. F. Ziegler, Nucl. Instrum. Methods B 219-220, 1027 (2004).

${ }^{14}$ P. H. Dederichs, J. Phys. F: Metal Phys. 3, 471 (1973).

${ }^{15}$ S. Takeda, Inst. Phys. Conf. Ser. (IOP Publishing Ltd, 1997), Vol. 157.

${ }^{16}$ J. Li and K. Jones, Appl. Phys. Lett. 73, 3748 (1998).

${ }^{17}$ A. Claverie, B. Colombeau, B. de Mauduit, C. Bonafos, X. Hebras, G. Ben Assayag, and F. Cristiano. Appl. Phys. A 76, 1025 (2003).

${ }^{18}$ S. Boninelli, N. Cherkashin, A. Claverie, and F. Cristiano, Appl. Phys. Lett. 89, 161904 (2006).

${ }^{19}$ R. Crosby, K. S. Jones, M. E. Law, A. Nylandsted Larsen, and J. Lundsgaard Hansen, J. Vac. Sci. Technol. B 22, 1 (2004).

${ }^{20}$ G. Z. Pan, K. N. Tu, and A. Prussin, Appl. Phys. Lett. 68, 1654 (1996). 